The initial severity and extent of disease give a poor guide to the ultimate outcome of patients with ulcerative colitis, partly because the disease shows a tendency in many patients to extend proximally.

Further analysis, however, shows that the severity and extent during each year profoundly influence the course and outcome during that year. Each patient-year in which a severe attack of colitis occurs carries a risk to life of $14 \%$. Each patient-year in which there is total involvement of the colon and rectum carries a risk to life of $2.7 \%$, and this risk is relatively unaffected by age or duration of colitic symptoms. It is argued that patients with total involvement should therefore be recommended to undergo elective proctocolectomy ; for this form of treatment in the long run carries considerably less risk to life.
We are grateful to Dr. Richard Doll for his advice and criticism in the preparation of this paper.

\section{REFERENCES}

Bone, F. C., Ruffin, J. M., Baylin, G. J., and Cassel, C. (1950). Sth. med. f. (Bgham, Ala.), 43, 817.

Cullinan, E. R., and MacDougall, I. P. (1957). Lancet, 1, 487.

Edwards, F. C., and Truelove, S. C. (1963). Gut, 4, 299.

Flood, C. A., Lepore, M. J., Hiatt, R. B., and Karush, A. (1956). F. chron. Dis:, 4, 267.

Kellock, T. D., and White, B. (1957). Gastroenterologia (Basel), 88, 13. Pulvertaft, C. N. (1964). Brit. F. Surg., 51, 414.

Tanner, N. C. (1950). Proc. roy. Soc. Med., 43, 147.

Truelove, S. C.., and Witts, L. J. (1955). Brit. med. F., 2, 1041.

Watts, J. McK., de Dombal, F. T., Watkinson, G., and Goligher, J. C. (1966). In press.

\title{
Electrocardiogram in Alcoholism and Accompanying Physical Disease
}

\author{
R. G. PRIEST,* M.B., M.R.C.P.ED., D.P.M. ; J. K. BINNS, † M.B., M.R.C.P.ED., D.P.M.
}

A. H. KITCHIN, $\ddagger$ PH.D., M.R.C.P., M.R.C.P.ED.

Brtt. med. F., 1966, 1, 1453-1455

Evans (1959) drew attention to various abnormalities in the electrocardiogram (E.C.G.) found in those alcoholics presenting primarily with physical symptoms. Stimulated by this, and the subsequent annotations in the British Medical fournal (1960) and the Lancet (1960), the present study was undertaken to determine the extent of electrocardiographic changes and concomitant physical disease in alcoholics presenting as psychiatric problems.

\section{Method}

Thirty-seven consecutive patients admitted on account of alcoholism to the amenity-bed section (Craig House) of the Royal Edinburgh Hospital were screened by routine recording of standard 12-lead E.C.G.s (the Honeywell Cardioview, a transistorized portable machine, was used) before treatment was started. Treatment was with parenteral vitamins (Parentrovite), withdrawal of alcohol, substitution in the first instance by paraldehyde, and later, in most cases, with tranquillizers. Phenothiazines were generally avoided in view of the findings af Kelley et al. (1963) of T-wave changes even in low dosage (200 mg. thioridazine daily). In general chlordiazepoxide (Librium) was preferred. The E.C.G. was repeated at suitable intervals during admission.

Other data recorded included duration of history and daily intake of alcohol as admitted by the patient, age, height, weight, tobacco consumption, cardiovascular symptoms and physical signs, clinical and biochemical signs of liver abnor-

* Royal Edinburgh Hospital for Nervous and Mental Disorders. Now at Department of Psychiatry, University of Edinburgh.

t Royal Edinburgh Hospital for Nervous and Mental Disorders. Now at Leverndale Hospital, Glasgow.

‡Western General Hospital, Edinburgh. mality, presence of delirium tremens, and signs of peripheral neuropathy or of organic cerebral disease (including memory disorders). It was not possible to obtain complete information on every subject owing sometimes to lack of cooperation or premature self-discharge against medical advice.

\section{Findings in the E.C.G.}

Seventeen patients had normal E.C.G.s. Twenty had some abnormality of the varieties detailed below. Of these 20 repeat E.C.G.s were obtained in 16 after an interval of two days to three months.

Abnormalities in the E.C.G. included atrial fibrillation, nodal rhythm, and right bundle-branch block. Temporary depression of the ST segment was present in three cases. In two of these cloven $T$ waves were present. All cases reverted to isoelectric ST segments within a few days of admission. An example is shown in Fig. 1.

$T$-wave Changes.-Characteristic changes in the configuration of the $T$ wave in alcoholic cardiomyopathy have been

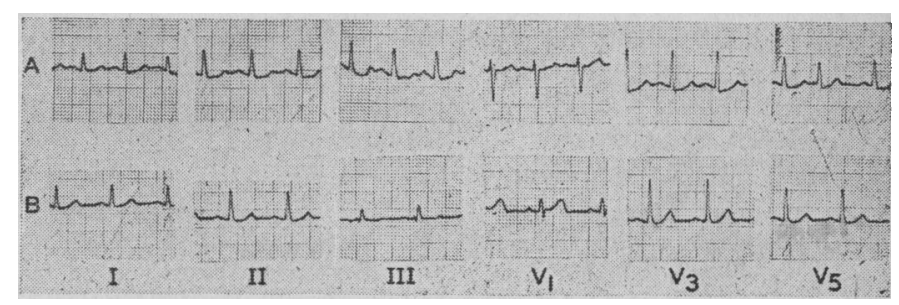

FIG. 1.-E.C.G. of a 45-year-old man. A, on admission with acute alcoholism, and B, one week later, after treatment. Note ST-T changes reverting to normal. 
described by Evans. The changes are usually apparent in the precordial leads. The abnormal $T$ waves have been classified as spinous-that is, tall, narrow, and peaked-cloven, when the normal positivity of the wave is interrupted by a dip at the peak, and the so-called dimple $T$ wave, consisting of a diminutive symmetrical negative deflection (Fig. 2).

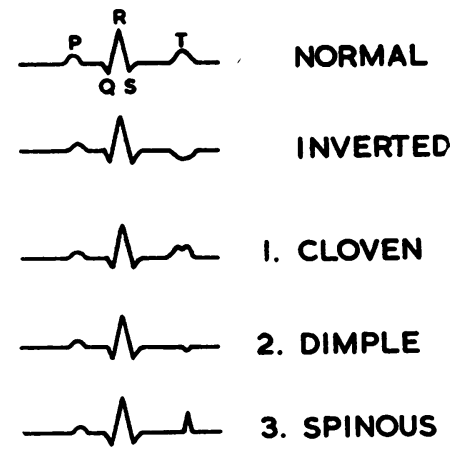

FIG. 2.-The three $T$-wave changes in alcoholism.

In the present series only one example of the spinous type was found. Twelve patients had cloven $T$ waves (Fig. 3), and two had the dimple variety. In addition, one patient had flat isoelectric $T$ waves, and in three further cases the $T$ wave was inverted in the left ventricular leads but did not have the characteristic appearance of the dimple wave.

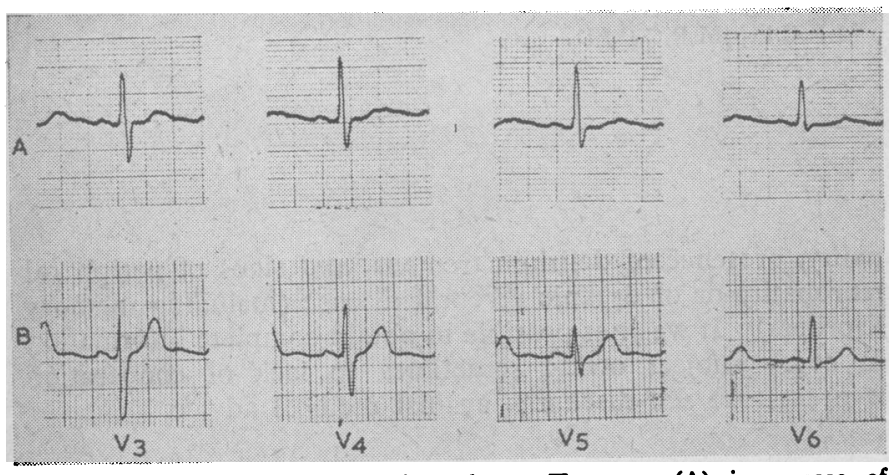

FIG. 3.-Precordial leads showing cloven $T$ waves $(A)$ in a case of alcoholism reverting to normal (B) after 10 days.

Regression of T-wave Changes.-In the literature the presence of $\mathrm{T}$-wave changes has generally been thought to indicate permanent myocardial damage, and the electrographic abnormality has been reported as persistent. In the present series, however, a large proportion of the $T$-wave abnormalities did regress. These included the instance of a spinous wave, both the dimple-type waves, and one of the three frankly inverted waves. Serial E.C.G.s were available in nine of the 12 cases with cloven $T$ waves, and in seven of these nine the abnormality disappeared.

\section{Comment on E.C.G. Findings}

Previous studies have suggested that alcohol is an important cause of cardiomyopathy (Brigden, 1957 ; Hickie and Hall, 1960 ; Wendt et al., 1962 ; Burch et al., 1963). Evans (1959, 1964) has described T-wave changes in alcohol cardiomyopathy that he regards as distinctive (dimple, cloven, and spinous). Brigden and Robinson (1964), discussing 50 patients with this condition, state that abnormalities of the $T$ waves with this condition, state the dimple wave in some, but are "reluctant to attach diagnostic significance to any pattern in this disorder."

All the series quoted have dealt with patients presenting to the general physician, and, so far as is known, no study has attempted to estimate the frequency with which these changes occur among alcoholics as a whole. The present study was an attempt to determine the frequency of electrocardiographic changes in alcoholics presenting to the psychiatrist.

It seems reasonable to assume that the electrocardiographic abnormalities are related to the alcohol rather than directly to any psychiatric abnormality. Changes in the E.C.G. have been described with gross cerebral disease (Harrison and Gibb, 1964 ; Zondek, 1964), but these changes tend to be extensive and resemble patterns of ischaemia or infarction. Other electrocardiographic changes have been described in schizophrenia (Wendkos, 1963), but this diagnosis was considered in only two of our patients.

The high incidence of abnormalities in the E.C.G.s of these patients, in whom other forms of heart disease were not detected, seems unlikely to be due to chance. The incidence of $\mathbf{T}$-wave abnormalities (flat, diphasic, or inverted) in screened healthy working-men is less than $1 \%$ in all the large series reported (Averill and Lamb, 1960 ; Blackburn et al., 1960 ; Simonson, 1961), and Simonson concludes that such major recognizable electrocardiographic abnormalities are much more likely to be due to pathological change than to normal variation. Also, the fact that in so many cases the abnormality was temporary and disappeared after treatment is strong evidence of a link with alcoholic intoxication. In most of the cases the abnormality corresponded to the types described by cardiologists as characteristic of patients presenting with heart failure of alcoholic aetiology. The difference in this series is that none of the patients had serious cardiac symptoms or showed evidence of heart failure; all in fact were referred to hospital on psychiatric grounds. This suggests that electrocardiographic abnormalities may precede the development of myocardial impairment. In addition, the fact that the abnormalities are reversible suggests that they may not, at least in the early stages, be attributable to myocardial damage but to reversible metabolic causes, perhaps a direct effect of alcohol itself or a breakdown in an enzymatic process.

\section{Other Physical Findings}

Apart from abnormal E.C.G., the next commonest abnormality was a large or tender liver (in 15 patients). None of the other abnormalities was present in more than nine of the patients recorded (see Table). Altogether there were only five patients with no apparent physical abnormalities, and a further two who had symptoms only.

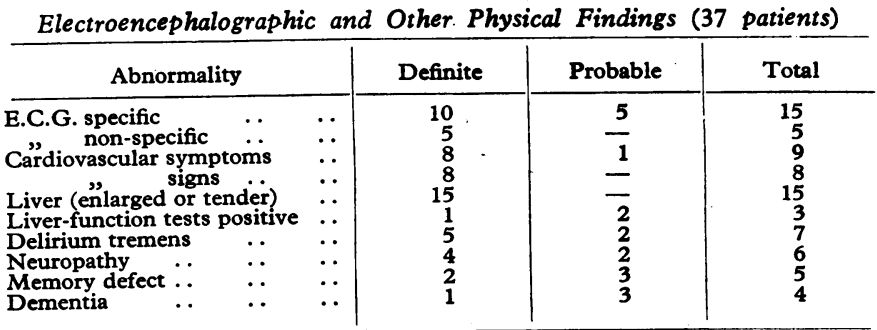

\section{Correlations and Discussions}

We were interested to see if the presence of electrocardiographic changes was correlated with any of the other physical abnormalities, and also to see if there were any statistically significant correlations of the other physical findings among themselves.

We used Kendall's (1955) tau test, which not only tests the significance but also gives a measure of the strength of the association. The tau test is complex and lengthy, and, as we 
were doing many of them, we used the Atlas Computer (Rees, 1964).

Correlation of electrocardiographic changes with the other variables showed that the abnormal E.C.G.s were significantly associated with body-weights in that specific changes occurred seldom in underweight patients (tau $=0.44 ; \mathrm{P}=0.02$ ) and never in our obese patients (tau $=-0.46 ; \mathrm{P}=0.02$ ), which contrasts with previous observations (Evans, 1959) that patients with these changes tend to be overweight. Our results also suggested that the specific E.C.G. abnormalities correlated with height (less common in the tall, tau $=-0.25, \mathrm{P}=0.1$ ), with the presence of abnormal cardiovascular signs, and with the absence of peripheral neuropathy, but the last two correlations are significant only at the $\mathbf{P}=0.2$ (approximately) level.

In considering the intercorrelations between abnormalities other than E.C.G. it was found that the admitted daily intake of alcohol was positively correlated with the presence of peripheral neuropathy (tau $=-0.44 ; \mathrm{P}=0.028$ ), as might be expected, but that it was negatively correlated with the presence of delirium tremens (tau $=-0.40 ; \mathrm{P}=0.036$ ) and with liver tenderness or enlargement (tau $=-0.43 ; \mathrm{P}=0.036)$.

\section{Summary}

In a series of 37 psychiatric in-patients with alcoholism 20 had abnormal E.C.G.s. The usual changes found were those described by Evans as specific for alcoholic cardiomyopathy (dimple and cloven $\mathrm{T}$ waves); many reverted to normal during hospital admission. An abnormal E.C.G. was the physical abnormality most often found in these patients.

The abnormal E.C.G.s were significantly associated with body-weight, occurring seldom in underweight patients (tau $=-0.44 ; \mathrm{P}=0.02$ ), and never in our obese patients (tau $=$ $-0.46 ; \mathbf{P}=0.02)$. They showed a tendency to occur in the presence of abnormal cardiovascular signs.
The liver was enlarged or tender in 15 of the 37 patients (but in only one were the flocculation tests unequivocally abnormal).

In considering the physical health of the patients in this series, relevant symptoms, physical signs, or abnormalities of special investigations were found in 32 of the 37 patients.

We are grateful to Mr. D. J. Rees for preparing the computer programme, to Dr. K. Hope for advising on the statistical method, and to Dr. E. E. Robertson for permission to report on the patients under her care. The Honeywell Cardioview portable electrocardiograph was kindly lent by Vitamins Limited, and the work was supported by a grant from the Royal Edinburgh Hospital.

Note.-For reasons of brevity it has not been possible to give the complete data and statistical treatment, but details will gladly be furnished on request.

\section{REFERENCES}

Averill, K. H., and Lamb, L. E. (1960). Amer. F. Cardiol., 6, 76. Blackburn, H., Keys, A., Simonson, E., Rautaharju, P., and Punsar, S. (1960). Circulation, 21, 1160.

Brigden, W. (1957). Lancet, 2, 1179, 1243.

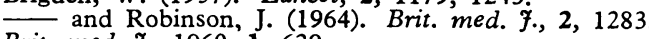

Brit. med. f., 1960, 1, 629.

Burch, G. E., Walsh, J. J., and Black, W. C. (1963). F. Amer. med. Ass., 183,81 .

Evans, W. (1959). Brit. Heart F., 21, 445.

- (1964). Progr. cardiovas. Dis., $7,151$.

Harrison, M. T., and Gibb, B. H.' (1964). Lancet, 2, 429.

Hickie, J. B., and Hall, G. V. (1960). Aust. Ann. Med., 9, 258.

Kelly, H. G., Fay, J. E., and Laverty, S. G. (1963). Canad. med. Ass. F. 89, 546.

Kendall, M. G. (1955). Rank Correlation Methods, 2nd ed. Griffin,
London. London.

Lancet, 1960, 1, 536.

Rees, D. J. (1964). Guide to a Survey Program for Atlas Computer Unit Report No. 2.

Simonson, E. (1961). Differentiation between Normal and Abnormal in Electrocardiography. Mosby, St. Louis.

Wendkos, M. H. (1963). Clin. Res., 2, 255.

Wendt, V. E., Stock, T. B., Hayden, R. O., Bruce, T. A., Gudbjarnason, S., and Bing, R. J. (1962). Med. Clin. No. Amer., 46, 1445. Zondek, H. (1964). Lancet, $2,1018$.

\title{
Incidence and Significance of Melanogenuria
}

\author{
J. C. CRAWHALL,* M.B., B.S., PH.D. ; BARBARA J. HAYWARD, $\dagger$ B.SC. ; C. A. LEWIS, $\dagger$ PH.D., A.R.I.C.
}

Brit. med. F., 1966, 1, 1455-1457

Some patients with malignant melanoma excrete urine containing abnormal metabolic products which darken on exposure to air and react under certain conditions with sodium nitroprusside to give a characteristic blue colour (Thormählen, 1887). This phenomenon is not found in the early stages of the disease, and Eppinger (1910) has suggested that it appears after the development of hepatic metastases.

The abnormal metabolites (melanogens) fall into two chemical classes-the phenol melanogens (3:4-dihydroxyphenylalanine and its metabolite, homovanillic acid), which are Thormählennegative (Duchon and Gregora, 1962 ; Scott, 1962), and the indole melanogens, which are Thormählen-positive and react characteristically with Ehrlich's p-dimethylaminobenzaldehyde reagent. Leonhardi (1954) and Duchon and Pechan (1963) effected the chromatographic separation of at least three Thormählen-positive substances, thought to be conjugation products of 5:6-dihydroxyindole. Pechan (1959) has evaluated

\footnotetext{
* Medical Professorial Unit, St. Bartholomew's Hospital, London. Temporary address, Clinical Centre, National Institutes of Health, Bethesda, Maryland, U.S.A.

† Department of Biochemistry, St. Bartholomew's Hospital Medical Colle ze, London.
}

the optimum conditions for the spectrophotometric determination of melanogens by the Thormählen reaction.

The biochemical and clinical significance of the melanogens has been review recently by Duchon and Pechan (1963).

In this investigation we have used paper chromatography and spectrophotometry as double criteria in a study of the incidence and extent of melanogen excretion in relation to the clinical state of the patient. We have studied the effect of cytotoxic drug therapy on melanogen excretion, and have made a comparison of plasma and urinary melanogen excretion and urinary melanogen concentration.

\section{Methods}

Analyses of urinary indole melanogens by paper chromatography and by a quantitative Thormählen technique were performed on early-morning specimens from every patient entering this hospital as an in-patient during 14 months in whom at any time a confirmed diagnosis of malignant melanoma had been made. If a positive result was obtained further analyses were made on 24-hour collections. Analyses were also per- 